\title{
An experimental study of sunflower husk pellets combustion
}

\author{
Svetlana Islamova, Julia Karaeva*, Svetlana Timofeeva and Aidar Kadyirov \\ Institute of Power Engineering and Advanced Technologies, FRC Kazan Scientific Center, Russian Academy of Sciences, Kazan, \\ 420111, Russia
}

\begin{abstract}
The thermogravimetric study of the sunflower husk pellets combustion was carried out at three heating rates: 5,10 , and $20^{\circ} \mathrm{C} / \mathrm{min}$ to increase the efficiency of agricultural waste disposal methods. The husk combustion process can be divided into several stages: the stage of moisture evaporation and the release of light fractions of volatile substances, the main stage of the release of volatiles and combustion, as well as the stage of the carbonaceous residue after-burning. The maximum mass loss was observed in the experiment with a heating rate of $10{ }^{\circ} \mathrm{C} / \mathrm{min}$, and it was equal to $91.99 \%$ of the total weight of organic matter. The average residual mass for all experiments was 3\%. The higher heating value (HHV) of sunflower husk pellets was $19.2 \mathrm{MJ} / \mathrm{kg}$. When implementing a biomass boiler with a capacity of $430 \mathrm{~kW}$, the return period will be 3.43 years.
\end{abstract}

\section{Introduction}

Resources conservation in agriculture plays an important role. The recycling of waste into secondary raw materials is of particular interest, since this allows eliminating or reducing the negative impact on the environment. Modern waste recycling technologies also make it possible to extract all valuable components from recyclable raw materials and produce value-added products from them. The recycling of agricultural waste contributes to the formation of a circular economy, i.e., economic development along a circular path.

Agriculture is the sector with the highest biomass production, its use contributes not only to reducing the use of fossil fuels and greenhouse gas emissions but also to the development of 'green markets', new jobs, the production of high-tech products (food, feed, bioproducts, and bioenergy) [1]. Thus, crop wastes are the large-tonnage source for the development of bioeconomics.

The production of sunflower (Helianthus annuus L.) in the world in the 2020/2021 crop year was 50 million tons. Currently, the leaders are Ukraine (28\%), Russia (27\%), the European Union (18.4\%), and China (6.6\%). It should be noted that sunflower is one of the most important oil-bearing crops. However, after its processing, a significant amount of waste remains in the form of husk.

Sunflower husk is widely used and can be used as a resource for generating heat and electrical energy [2, 3], motor-fuel hydrocarbon fractions [4], as well as for obtaining polymer biocomposites [5], feed additives [6].

Sunflower husk pellets are often used for combustion in domestic and industrial boilers. The amount of generated carbon dioxide is comparable to the amount that a plant absorbs during its growth for photosynthesis.
The work [7] notes that pellets from sunflower husk are used at coal-fired power plants more often than pellets from other types of biomass.

The work [8] found that pellets from sunflower husks can be combusted in circulating fluidized bed boilers.

A mixture of 5\% biomass and $95 \%$ solid fuel can be fired in a pulverized coal-fired, dry-bottom boiler; $20 \%$ biomass and $80 \%$ solid fuel in cyclone-furnace boilers. Purely $(100 \%)$ biomass pellets can be used in grate stokers at small power plants [20].

The work [9] considers the combustion of sunflower husk in pulverized coal-fired boilers.

The work [10] considers various options for the use of cogeneration plants using sunflower husks as fuel. Such cogeneration plants will reduce carbon dioxide emissions by $200-300 \%$ and increase total revenue to $65.7 \%$.

The paper [11] presents the emissions of hazardous substances after burning sunflower husk pellets in an industrial Greek manufactured fixed bed biomass boiler (2.3 MWth). Emissions of $\mathrm{SO}_{2}$ and $\mathrm{NO}_{x}$ gases are within the established standards, however, the dust content significantly exceeds the maximum permissible concentration.

It should be noted that ash obtained from sunflower husk pellets combustion is also a valuable product. For example, in [12], it was reused for the production of ceramics. Sunflower seed husk biochar was used as a biosorbent for removing copper ions and wastewater decontamination [13]. Besides, sunflower husk ash can be used as fertilizer [14].

The features of thermochemical conversion of given biomass fuel can be studied using thermogravimetric analysis (TG analysis). The advantages of this method are a quick assessment of the fuel quality, determination of the total combustion time, stages of thermal

\footnotetext{
* Corresponding author: julieenergy@list.ru
} 
decomposition, temperatures of the beginning and end of the process, as well as stages and the amount of ash [15].

The work [15] presents the results of numerical and experimental studies of the sunflower husk pellets combustion in domestic boilers. TG analysis of the pellets was carried out at a heating rate of $10^{\circ} \mathrm{C} / \mathrm{min}$ in an oxygen atmosphere. However, the study of a single heating rate is not enough to study the kinetics of the combustion process.

This work aims to study the thermal decomposition of sunflower husk pellets to analyze the possibilities of their use as an energy resource. TG analysis was carried out at heating rates of 5,10 , and $20^{\circ} \mathrm{C} / \mathrm{min}$ in an oxidizing environment, which makes it possible to study the kinetics of thermochemical conversion of plant raw materials.

\section{Materials and methods}

\subsection{Sunflower husk pellets}

Samples of granulated sunflower husk were obtained at the Kazan oil extraction plant (Russia). Sunflower husk pellets had a diameter of $8 \mathrm{~mm}$ and a length of about 20 $\mathrm{mm}$ (Fig. 1); the density was $1000-1400 \mathrm{~kg} / \mathrm{m}^{3}$. Before the start of the experiment, the sunflower husk granules were dried to an air-dry state at $105{ }^{\circ} \mathrm{C}$ for one hour in an ShSL-43/250V drying cabinet (Russia).

The CHNS analyzer EuroEA3000 (Italy) was used to determine the content of carbon, hydrogen, oxygen, and nitrogen in the samples of sunflower husk. The samples were weighed in tin capsules on a Sartorius CP2P microbalance (Germany). Callidus 4.1 software was used to quantify and evaluate the obtained data. Moisture, bulk density, ash content and volatile content of pellet samples were measured in accordance with BS EN ISO 18134-3:2015, BS EN ISO 18122:2015, BS EN ISO 18123:2015. The heat of combustion of the samples under study was determined using an IKA C200 calorimeter (Germany).

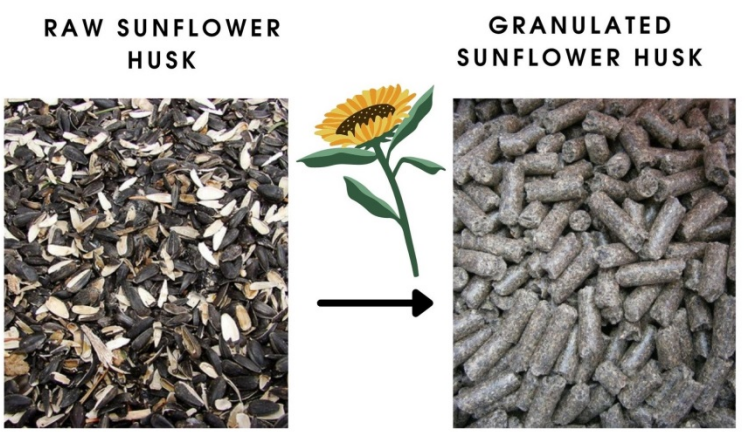

Fig. 1. Sunflower husk (raw and granulated)

Table 1 gives the thermal properties and elemental composition of sunflower husk samples (all values, except moisture, are given based on dry weight). The calorific value of sunflower husk is significantly higher than that of firewood (14.6-15.9 MJ/kg) and brown coal $(12.5 \mathrm{MJ} / \mathrm{kg})$. Combustion of sunflower granules is energy efficient since their ash content does not exceed $3 \%$, no harmful substances are emitted during combustion, and the amount of carbon dioxide does not exceed that formed during the natural decomposition of wood. Also, there are no pores in the granules, which prevents them from spontaneously igniting.

Table 1. Thermochemical characteristics of sunflower husk pellets

\begin{tabular}{|l|c|c|}
\hline \multicolumn{1}{|c|}{ Properties } & Unit & Value \\
\hline Crude fat & $\%$ & $3-5$ \\
\hline Crude fiber & $\%$ & $55-70$ \\
\hline \multicolumn{3}{|c|}{ Proximate analysis } \\
\hline Moisture & $\mathrm{W}^{\mathrm{p},} \%$ & $6.6-7.0$ \\
\hline Ash & $\mathrm{A}^{\mathrm{p}}, \%$ & $2.6-2.9$ \\
\hline Volatile matter & $\mathrm{V}^{\mathrm{daf}} \%$ & $77.5-77.6$ \\
\hline Calorific value & $\mathrm{HHV}, \mathrm{MJ} / \mathrm{kg}$ & 19.2 \\
\hline Fixed carbon & $\mathrm{FC}, \%$ & $12.5-12.9$ \\
\hline \multicolumn{3}{|c|}{ Ultimate analysis } \\
\hline C & $\%$ & 47.30 \\
\hline $\mathrm{H}$ & $\%$ & 6.50 \\
\hline $\mathrm{N}$ & $\%$ & 0.95 \\
\hline O & & 42.33 \\
\hline
\end{tabular}

\subsection{Thermogravimetric analysis}

The combustion experiment of granulated sunflower husk samples was simulated on a thermal analyzer SDT Q600 (TA Instrument, USA) (fig. 2).

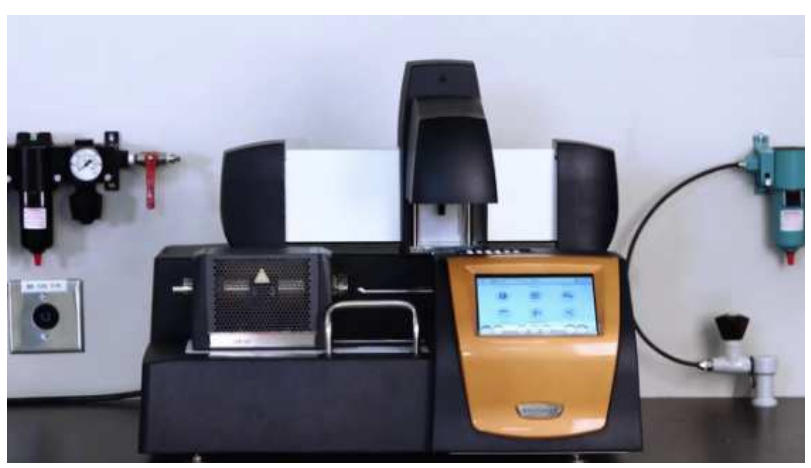

Fig. 2. Thermal analyzer SDT Q600

Before starting the research, samples of dried sunflower husk were ground, then about $10 \mathrm{mg}$ of the sample were placed in the equipment. The process temperature was uniformly increased from 24 to $700{ }^{\circ} \mathrm{C}$ at a heating rate of 5,10 , and $20 \mathrm{~K} / \mathrm{min}$ in air. The oxidizing environment was maintained by continuously supplying an air flow at a rate of $100 \mathrm{ml} / \mathrm{min}$. During the experiment, changes in the samples mass and processes accompanied by the release or absorption of heat were 
recorded. Profiles of TG analysis and differential scanning calorimetry (DSC) were obtained.

\section{Results and Discussion}

\subsection{Thermogravimetric analysis results}

Figs. 3 and 4 show the TG and DSC curves characterizing the thermal conversion process of the analyzed sunflower husk samples in the air. Analysis of the TG analysis curves showed that the oxidation of sunflower husk is accompanied by thermochemical transformations of its components [16].

Based on TG data, the husk oxidation process can be divided into several stages: the stage of moisture evaporation and the release of light fractions of volatiles, the main stage of the release of volatiles and combustion, and the stage of the carbonaceous residue after-burning, which is consistent with the data of other authors [15, 17]. Table 2 presents the main results of synchronous thermal analysis of sunflower husks at different heating rates.

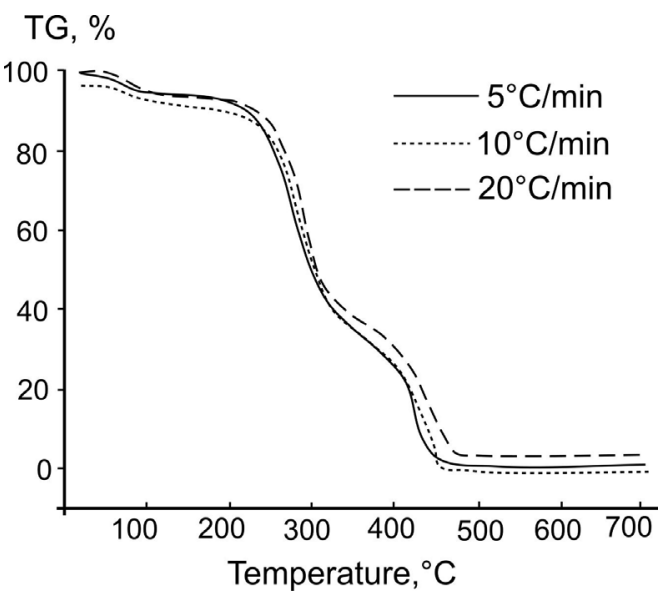

Fig. 3. TG curves of sunflower husk pellets

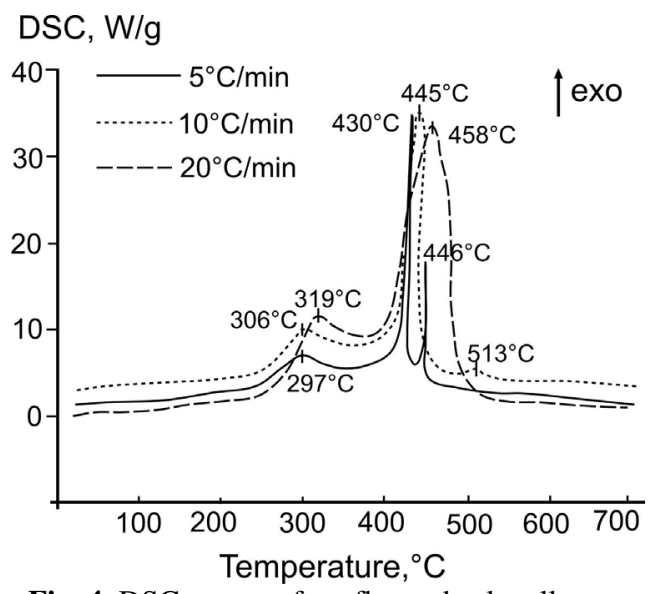

Fig. 4. DSC curves of sunflower husk pellets

At the stage of drying, mechanically bound moisture evaporates from the biomass surface, and physicochemically bound moisture evaporates from the inner surface of the pores. At the same time, in addition to drying, the decomposition process with the release of light volatiles from the husk begins. These processes are accompanied by energy absorption. The average mass loss for all heating rates is about $7.4 \%$.

Table 2. Temperature ranges of the main processes of sunflower husk pellets thermal decomposition

\begin{tabular}{|c|c|c|c|}
\hline \multirow{2}{*}{$\begin{array}{c}\text { Heating } \\
\text { rate, } \\
{ }^{\circ} \mathrm{C} / \mathrm{min}\end{array}$} & Drying & $\begin{array}{c}\text { Release of } \\
\text { volatiles and } \\
\text { combustion }\end{array}$ & $\begin{array}{c}\text { Carbonaceous } \\
\text { residue after- } \\
\text { burning }\end{array}$ \\
\cline { 2 - 4 } & $25 \ldots 190$ & $190 \ldots 425$ & $425 \ldots 700$ \\
\hline 5 & $25 \ldots 200$ & $200 \ldots 450$ & $450 \ldots 700$ \\
\hline 10 & $25 \ldots 210$ & $210 \ldots 475$ & $475 \ldots 700$ \\
\hline 20 & \multicolumn{3}{|c}{} \\
\hline
\end{tabular}

With an increase in temperature, the intensity of combustion and the rate of volatiles release increased. Then the main stage of the combustion process came, at which thermal effects took place. The heating rate influenced the temperature and the amplitude of the peaks corresponding to the thermal effect. At the heating rate of $5{ }^{\circ} \mathrm{C} / \mathrm{min}$, three exothermic peaks were observed at temperatures of 297,430 , and $446{ }^{\circ} \mathrm{C}$. At the heating rate of $10{ }^{\circ} \mathrm{C} / \mathrm{min}$, two exothermic peaks were observed at temperatures of 306 and $445{ }^{\circ} \mathrm{C}$. Combustion processes at this stage were associated with the interaction of the decomposition components of hemicellulose and cellulose with air. The greatest mass loss $(47-51 \%$ of the initial mass) occurred in the temperature range of $250-300{ }^{\circ} \mathrm{C}$ for both heating rates, which corresponded to the active thermal decomposition of cellulose.

The presence of oxygen in the gaseous medium increases the rate of thermal destruction of sunflower husk in the area of intense volatiles release, which is evident from the location of the TG-curves for all heating rates [18]. In the temperature range of 425-446 ${ }^{\circ} \mathrm{C}$, the maximum combustion temperature and heat release occurred, which corresponded to the active thermal decomposition of lignin in the sunflower husk samples [15]. The carbonaceous residue oxidation proceeded easily and quickly with the increase of the fixed carbon content and the fuel homogeneity.

Above $425{ }^{\circ} \mathrm{C}$, the combustion process slowed down in all experiments, the carbonaceous residue afterburning occurred, and therefore, no significant mass loss was observed. After the ending of flame combustion, smoldering began, which developed inside the remaining material. Perhaps this led to a small exothermic peak, which was observed at a temperature of $513{ }^{\circ} \mathrm{C}$ in an experiment with a heating rate of $5{ }^{\circ} \mathrm{C} / \mathrm{min}$. Smoldering continued as long as heat remained in the reaction surface region.

Table 3 shows that the maximum mass loss was observed in the experiment with a heating rate of $10{ }^{\circ} \mathrm{C} / \mathrm{min}$ and it was $91.99 \%$ of the total organic matter mass. Consequently, in this experiment, the processes of thermal destruction of the base substance and carbon burnout occurred most fully. The average value of the residual mass for all experiments was $3 \%$, the value of which was related to the content of the ash residue mineral components. 
Table 3. TG analysis results at different heating rates

\begin{tabular}{|c|c|c|c|c|}
\hline \multirow{2}{*}{$\begin{array}{c}\text { Heating } \\
\text { rate, } \\
{ }^{\circ} \mathrm{C} / \mathrm{min}\end{array}$} & Drying & $\begin{array}{c}\text { Release of } \\
\text { volatiles } \\
\text { and } \\
\text { combustion }\end{array}$ & $\begin{array}{c}\text { Carbonaceous } \\
\text { residue after- } \\
\text { burning }\end{array}$ & $\begin{array}{c}\text { Residue } \\
\text { mass at } \\
700{ }^{\circ} \mathrm{C}\end{array}$ \\
\hline 5 & 7.32 & 86.22 & 5.25 & 1.21 \\
\hline 10 & 7.27 & 91.99 & 0.7 & 0.4 \\
\hline 20 & 7.57 & 83.88 & 5.42 & 3.13 \\
\hline $\begin{array}{c}\text { Average } \\
\text { value }\end{array}$ & 7.4 & 87.4 & 3.8 & 1.4 \\
\hline
\end{tabular}

Analysis of the obtained data showed a similar nature of the TG-curves location, which correspond to different heating rates. However, their displacement relative to the ordinate axis was observed. With an increase in the heating rate from 5 to $20{ }^{\circ} \mathrm{C} / \mathrm{min}$, the main physicochemical processes of husk oxidation were completed at a higher temperature. This is because the nature of the destruction of the bonds of the carboncontaining material under thermal action depends on the heating rate.

At slow heating, the weakest chemical bonds were destroyed, and at a higher heating rate, the thermal destruction of components was accelerated and shifted towards higher temperatures [19]. As the heating rate increased, the peak heights corresponding to the endo- or exothermic effect also began to increase. The location of the peaks on the DSK curves shifted towards higher temperatures, their depth increased. The peak corresponding to a heating rate of $10{ }^{\circ} \mathrm{C} / \mathrm{min}$ is characterized by the maximum value of the thermal effect in comparison with other rates.

\subsection{Comparative analysis}

Additionally, a comparison between a boiler using sunflower husk pellets and a boiler using fuel oil M 100 was made (Table 4). The calculation was carried out, taking into account Russian fuel prices, according to the method presented in [2]. The price of pellets is lower, but more of them are required to obtain the same power. This amount of pellets can be easily obtained in sunflower oil factories. When using biomass, the annual costs were $51.1 \%$ less. The investment was $32,000 €$, and considering the produced annual savings of $9,320.8 €$, a return period of 3.43 years was obtained.

Table 4. Comparative analysis between the boilers

\begin{tabular}{|l|c|c|}
\hline \multicolumn{1}{|c|}{ Parameter } & $\begin{array}{c}\text { Biomass } \\
\text { Boiler }\end{array}$ & $\begin{array}{c}\text { Conventional } \\
\text { Boiler }\end{array}$ \\
\hline Fuel & $\begin{array}{c}\text { Sunflower } \\
\text { husk pellet }\end{array}$ & $\begin{array}{c}\text { Fuel oil M } \\
100\end{array}$ \\
\hline Price, $€ / \mathrm{kg}$ & 0.04 & 0.20 \\
\hline Installation power, kW & 430 & 430 \\
\hline Boiler efficiency, \% & 80 & 90 \\
\hline Fuel consumption, kg & $222,615.8$ & $96,126.9$ \\
\hline Annual cost & $8,904.6$ & $18,225.4$ \\
\hline Annual saving, \% & 51.1 & - \\
\hline
\end{tabular}

\section{Conclusion}

The study of the sunflower husks combustion in the air was carried out at three heating rates: 5, 10, and $20{ }^{\circ} \mathrm{C} / \mathrm{min}$ using the TG analysis method. The husk combustion process can be divided into several stages: the stage of moisture evaporation and the release of light fractions of volatile substances, the main stage of the release of volatiles and combustion, as well as the stage of the carbonaceous residue after-burning. In the temperature range of $425-446{ }^{\circ} \mathrm{C}$, the maximum combustion temperature, and heat release occurred, which corresponded to the active thermal decomposition of lignin in the sunflower husk samples. The maximum mass loss is observed in the experiment with a heating rate of $10{ }^{\circ} \mathrm{C} / \mathrm{min}$, and it is $91.99 \%$ of the total organic matter mass. Consequently, in this experiment, the processes of thermal destruction of the base substance and carbon burnout occur most fully. The temperature peak corresponding to a heating rate of $10{ }^{\circ} \mathrm{C} / \mathrm{min}$ in the DSC curves is also characterized by the maximum value of the thermal effect in comparison with other rates. The average value of the residual mass for all experiments is $3 \%$, the value of which is related to the content of the ash residue mineral components.

The obtained results of experimental studies of sunflower husks can be used when modeling the combustion and thermal decomposition of agricultural waste and ligno-containing biomass, and choosing the optimal operating conditions for power plants.

The comparison of a biomass boiler and a boiler using traditional fuel showed that it is possible to cut in half the annual fuel costs.

\section{References}

1. M. Duque-Acevedo, L.J. Belmonte-Ureña, F.J. Cortés-García, F. Camacho-Ferre, Glob. Ecol. Conserv., 22, e00902 (2020).

2. M.-A. Perea-Moreno, F. Manzano-Agugliaro, A.J. Perea-Moreno, Sustainability, 10, 3407 (2018).

3. K. Roman, J. Barwicki, M. Hryniewicz, D. Szadkowska, J. Szadkowski, Processes, 9(2), 364 (2021).

4. V.B. Il'in, G.B. Narochnyi, A.F. Zubenko, A. A. Savost'yanov, R. E. Yakovenko, Solid Fuel Chem., 55, 54-61 (2021).

5. M. Barczewski, K. Sałasińska, J. Szulc, Polym. Test., 75, 1-11 (2019).

6. S.K. Mustafayev, E.O. Smychagin, Proceedings of the International Conference "Actual Issues of Mechanical Engineering" (AIME 2018), 157, 429 434 (2018).

7. M. Kułażyński, S. Jabłoński, J. Kaczmarczyk, Ł. Świątek, K. Pstrowska, M. Łukaszewicz, J. Energy Inst., 91(5), 668-675 (2018).

8. K. Kaczyńska, K. Kaczyński, P. Pełka, E3S Web of Conferences, 82, 01007 (2019). 
9. D.V. Sosin, D.S. Litun, I.A. Ryzhii, A.V. Shtegman, N.A. Shaposhnikov, Therm. Eng., 67, 10-16 (2020).

10. V. Havrysh, A. Kalinichenko, G. Mentel, U. Mentel, D.G. Vasbieva, Energies, 13, 361 (2020).

11. M.A. Kougioumtzis, I.P. Kanaveli, E. Karampinis, P. Grammelis, E. Kakaras, Renew. Energy, 171, 516-525 (2021).

12. N.E. Quaranta, G.G. Pelozo, A. Cesari, A.A. Cristóbal, WIT Trans. Ecol. Environ., 203, 1323 (2016).

13. M.E. Saleh, A.A. El-Refaey, A.H. Mahmoud, Soil Water Res., 1, 53-63 (2016).
14. R. Paleckienè, A.M. Sviklas, R. Šlinkšienè, V. Štreimikis, Pol. J. Environ. Stud., 19(5), 973-979 (2010).

15. A. Bala-Litwiniak, M. Zajemska, Renew. Energy, 162, 151-159 (2020).

16. P.J. De Wild, H. Reith, H.J. Heeres, Biofuels, 2(2), 185-208 (2011).

17. C. He, A. Giannis, J.-Y. Wang, Appl. Energy, 111, 257-266 (2013).

18. O.M. Larina, V.A. Sinelshchikov, G.A. Sytchev, High Temp., 58, 710-715 (2020).

19. J.V. Karaeva, S.S. Timofeeva, V.N. Bashkirov, K.S. Bulygina, Biomass Conv. Bioref. (to be published). 